\title{
Preoperative lymphoscintigraphy and triangulated patient body marking are important parts of the sentinel node process in breast
}

\section{cancer}

\author{
Borys R Krynyckyi*, Suk Chul Kim and Chun K Kim
}

\begin{abstract}
Address: Department of Radiology, Division of Nuclear Medicine, The Mount Sinai School of Medicine, The Mount Sinai Hospital, New York, New York, USA

Email: Borys R Krynyckyi* - syrob@msn.com; Suk Chul Kim - sukchulkim@gmail.com; Chun K Kim - chun.kim@msnyuhealth.org

* Corresponding author
\end{abstract}

\section{Published: 24 August 2005}

World Journal of Surgical Oncology 2005, 3:56 doi:10.1/86/1477-7819-3-

56

This article is available from: http://www.wjso.com/content/3/l/56

(C) 2005 Krynyckyi et al; licensee BioMed Central Ltd.

This is an Open Access article distributed under the terms of the Creative Commons Attribution License (http://creativecommons.org/licenses/by/2.0), which permits unrestricted use, distribution, and reproduction in any medium, provided the original work is properly cited.
Received: 17 June 2005

Accepted: 24 August 2005

\section{Introduction}

Failure to visualize or correctly visualize sentinel nodes (SN) during preoperative lymphoscintigraphy (LS) is a frustrating problem. Most of these instances occur due to inexperience in performing the studies, and can be realized and corrected with the use of proper technique, even in centers that do not have state of art equipment. This is now becoming a major issue, as more and more sentinel node biopsies are being performed, and will increasingly gain more importance once sentinel lymph node biopsy (SLNB) becomes the standard of care in patients with breast cancer world wide.

Pandey et al. [1] has recently reported two unfortunate experiences with LS during SLNB. From the images and the description of the cases, it appears that the studies were suboptimal in both imaging and injection technique, and understandably, completely frustrating to any surgeon.

In the second case, contamination of the patient by stray radioactivity from the perilesional injections is suggested by the authors as the cause of the superior focus that appeared in the supracalvicular region [1]. Actually, true contamination is very easy to realize with proper imaging technique [2-4]. When multiple angled views $\left(0^{\circ}, 45^{\circ}\right.$, $90^{\circ}$ ) are obtained, including standing/sitting views and triangulated body marking (TBM), contamination is extremely unlikely to be missed, as it is always surface based. In over 2000 LS cases we have performed, the very rare stray activity has always been picked up for what it is, before the patient is presented to the surgeons [2-4].

In the first case, a $\mathrm{SN}$ was hidden by the injected perilesional activity [1]. This is a known issue when the primary lesion is located near the axilla itself. Multiple strategies exist for dealing with diffusion and scatter from the injection site hiding the adjacent $\mathrm{SNs}$ in the axilla, and are described below:

1) When performing perilesional injections of radiotracer, multiple angled views and standing views, which use gravity to markedly shift the injected activity inferiorly and medially away from the axillary SN compared to the supine position, are indispensable $[3,4]$. In addition, the perilesional injections should be on the side of the lesion away from the axilla to further lessen diffusion of activity from the injection site from obliterating the $\mathrm{SN}$ [3].

2) The volume of perilesional injections should be reduced when injecting close to the axilla to lessen diffusion and inherent scatter of activity (maintain below 3 ml) [3].

3) Upwardly offset energy windows can be used in the camera to reduce "relative" scatter in the images to help better see the SNs [2-4].

4) Proper image display techniques are critical; the images presented for the first case [1] appear to display subopti- 
mal adjustment as related to upper level, contrast/ gamma/threshold. Proper adjustment parameters are crucial for the delineation of a faint SN adjacent to intense activity from the injection site [4].

5) Yet, finally, an even better solution to the complexities of upper outer quadrant lesions, is to shift part or all of the injected dose to the areolar region [3-5]. This will largely or completely resolve the issues of injected activity/diffusion/scatter hiding a closely approximated SN in the axilla [3-5]. In addition, An Adaptive Injection Technique (AIT) can be employed to allow a limited control over the number of echelon nodes realized, and improve overall $\mathrm{SN}$ intensity. High injection volumes $(0.8-1.0 \mathrm{ml})$ administered over 1-2 minutes at the "areolar-cutaneous junction", referred to by us as LymphoBoost (LB), tend to nearly always delineate SNs (96.6\%-100\%) [4-6], and often multiple distant echelon nodes [3-7]. This is because these very shallow LB injections are extremely efficient at delivering activity to the $\mathrm{SN}$ compared to perilesional intraparenchymal injections, and even intradermal over the lesion injections [3-7]. Compared to concurrently administered perilesional and intradermal over the lesion injections, LB areolar injections, and other areolar type injections in general, delineate essentially the same primary nodes (excluding internal mammary nodes $[3,5,6]$ ) in the vast majority of patients, and do so with several times the efficiency of getting activity into the SN [3-7]. The LB areolar injections occasionally depict additional nodes closer to the injection site, the "reverse echelon node" (REN), a feature of areolar type injections in general related to injection location $[3,5,8]$. They also delineate additional conventional echelon nodes compared to perilesional injections [3,5-7]. There is preliminary evidence that low injection volumes $(0.1-0.3 \mathrm{ml})$ at the areolarcutaneous junction tend to delineate fewer echelon nodes (which could be viewed as advantageous by some), and also result in fainter nodes, compared to high injection volumes (0.6-1.0 ml) [[5], (data pending publication)]. In addition, low injection volumes are also more prone to failure in delineating the SNs on LS as evidenced by a low $78.5 \%$ SN visualization rate during LS in a recent study by Rousseau et al. [9] when using very low volume $0.1 \mathrm{ml}$ injections of radiotracer in a manner similar to LB. Utilizing an AIT, the initial LB injection can be performed using a low or moderate volume of injection, if less echelon nodes are desired, optionally followed by an additional LB injection with a higher volume $(0.8-1.0 \mathrm{ml})$, if needed, when better $\mathrm{SN}$ delineation is required (more or brighter SNs). The need for a second injection is based on the viewing of sequential dynamic image sets obtained during the injection process [3-7]. Alternately, only a single high volume $(0.8-1.0 \mathrm{ml}) \mathrm{LB}$ injection can be performed for the study, as a means to simplify the process.
As judiciously mentioned in the case report by Pandey et al. [1], an additional cause of non-visualization of SNs on LS is extensive replacement of macrophages in the SNs by tumor. This can lead to non-visualization of SNs or SNs that are very faint, if visualized at all [9-11]. However, utilizing the AIT described above with LB injections, will usually maximize the activity in the SNs (many times more than with isolated perilesional injections) making the missed SN on LS images from tumor infiltration (because it is very faint) less likely.

We perform over half of our studies using a two day protocol, as this allows more time for the nuclear medicine department to work with the patient, allows us to take multiple angle and standing views, perform TBM, and eliminates the rush to complete the study and print the images. The two day protocol completely avoids creating any delays in the surgical schedule related to LS imaging and TBM, when surgery is performed the morning after the prior afternoon of imaging. It also allows surgery to be performed at centers remote from the location performing LS and TBM.

The often misunderstood [12-14] and least realized benefits of LS and TBM pertains to their ultimate purposes; i.e. providing a map of the nodes so the surgeons can reduce the amount of dissection performed during SLNB, thereby reducing the morbidity of the procedure of SLNB itself. Even if successful visualization of SNs occurred in only $50 \%$ of LS studies, their worth would still be priceless to these women, as a tool to further reduce morbidity during SLNB, compared to the potentially higher levels of morbidity when using only the probe without LS or TBM [1517].

Fortunately, 94.7\%-100\% of studies demonstrate SNs when using optimal techniques of areolar injection and various levels of LS image acquisition [4-6,17-21], making these underutilized tools of morbidity reduction applicable to nearly all women undergoing SLNB. This view appears to be in some ways shared by the authors in the case report by Pandey et al. [1], as a triple technique consisting of images, probe and dye is still suggested, regardless of the misfortunate LS events in the two cases presented [1].

In this light, the additional utility of standing/sitting views, with the arm out $90^{\circ}$ to the body axis, warrants further explanation. These views are the most accurate for delineating the true number of SNs in the axilla, as they separate bunched SNs that can appear as a cluster (single focus) on supine views $[3,4,22-28]$. They achieve this by shifting attenuating breast tissues away from the axilla (more SN counts), allowing the camera to be closer to the SNs (better SN resolution), shifting the injected activity 
away from the axilla (less scatter from injection site to hide SNs) and by stretching out the lymphatic channels from their overlapped/bunched state in the spine position, to their natural drawn out state when the patient is standing (better separation between SNs) [3,4,22-28]. By providing surgeons with a more accurate number and "relative" orientation of SNs in the woman's body, they can better plan on how extensive or selective their dissections are going to be, by more accurately knowing the number of nodes to expect.

Standing/sitting views are naturally not useful for TBM, which requires the patient to closely approximate the surgical position to be meaningful, i.e. triangulation performed on supine anterior and oblique views with the arm out in the $90^{\circ}$ surgical position. TBM has been previously described, and can help provide skin references regarding SN location for surgeons before incision $[2,3,26,27]$. Briefly, the technique consists of the following: with the woman supine, back flat against the imaging table with the arm in the surgical position, an anterior image is obtained and the SN is noted on the monitor and a mark (tape, pen marker, electronic) is made on the monitor screen surface over the SN seen on the monitor. A radioactive point source is brought into the field of view and moved along the woman's chest until it is positioned under the reference point on the monitor surface (the tape or marker point placed earlier on the screen surface while refreshing/updating the image), at which time the woman's body is marked with a indelible color marker. This is repeated in the $45^{\circ}$ projection, as lateral views are blocked by the arm in the surgical position. Triangulation into the body along the anterior and $45^{\circ}$ projection of the skin surface markings estimates $\mathrm{SN}$ location at the crossover point in the body $[2,3,16]$. The TBM technique can be useful in select patients by shorting the time of the initial probe survey during surgery. It can also help when decay has reduced the counts in the SNs when using two day protocols and in obese patients, where effective directionality and sensitivity of the probe are poor at the skin surface because of attenuation and increased distances from the SNs $[2,3,7,27,28]$. The technique of TBM will not accurately delineate the $\mathrm{SN}$ position when the breast position is different, arm position has shifted, or the patients torso is rotated differently during surgery compared to the position during chest marking during LS. These technical issues must be kept in mind when using the TBM method as an additional guide during the initial probe survey, and an agreed upon routine between surgeon and imaging specialist is required.

None of these techniques require the latest gamma camera equipment, in fact nearly all our studies are performed on cameras at least 12 years old [2-7]. What is required to obtain the best LS images and the most accurate TBM, is a full understanding of the issues and details involved in the techniques of injection, LS imaging and TBM [2$7,10,16,17,24,26-28]$.

\section{Abbreviations \\ SN Sentinel node}

LS Lymphoscintigraphy

SLNB Sentinel lymph node biopsy

TBM Triangulated body marking

AIT Adaptive injection technique

LB LymphoBoost

\section{Competing interests}

The author(s) declare that they have no competing interests.

\section{Authors' contributions}

BRK Conceived the manuscript.

SCK Assisted with conception, edited manuscript.

CKK Assisted with conception, edited manuscript.

\section{References}

I. Pandey M, Deo SVS, Maharajan R: Fallacies of preoperative lymphoscintigraphy in detecting sentinel node in breast cancer. World J Surg Oncol 2005, 3:31.

2. Krynyckyi BR, Miner M, Ragonese JM, Firestone M, Kim CK, Machac $\mathrm{J}$ : Technical aspects of performing lymphoscintigraphy: optimization of methods used to obtain images. Clin Nucl Med 2000, 25:978-985.

3. Krynyckyi BR, Kim CK, Goyenechea MR, Chan PT, Zhang ZY, Machac $\mathrm{J}$ : Clinical breast lymphoscintigraphy: optimal techniques for performing studies, image atlas, and analysis of images. Radiographics 2004, 24: I2I-145. discussion 139-145

4. Krynyckyi BR, Sata S, Zolty I, Kim CK, Knesaurek K: Reducing exposure from 57Co sources during breast lymphoscintigraphy by optimizing energy windows and other suggested enhancements of acquisition and the display of images. J Nucl Med Technol 2004, 32:198-205.

5. Krynyckyi BR, Kim CK, Mosci K, Fedorciw BJ, Zhang ZY, Lipszyc H, Machac J: Areolar-cutaneous "junction" injections to augment sentinel node count activity. Clin Nucl Med 2003, 28:97-107.

6. Krynyckyi BR, Chun H, Kim HH, Eskandar Y, Kim CK, Machac J: Factors affecting visualization rates of internal mammary sentinel nodes during lymphoscintigraphy. I Nucl Med 2003, 44: $1387-1393$.

7. Kim S, Kim CK, Krynyckyi BR: Areolar-cutaneous junction injection boosts activity in sentinel node by more than $\mathbf{5 0}$ times compared to perilesional injection: implications for morbidity reduction. Am Surg 2005, $71: 77-80$.

8. Roumen RM, Geuskens LM, Valkenburg JG: In search of the true sentinel node by different injection techniques in breast cancer patients. Eur J Surg Oncol 1999, 25:347-35I.

9. Rousseau C, Classe JM, Campion L, Curtet C, Dravet F, Pioud R, Sagan C, Bridji B, Resche I: The impact of nonvisualization of sentinel nodes on lymphoscintigraphy in breast cancer. Annals of Surgical Oncology 2005, I 2:533-538.

10. Kim SH, Shim J, Kim CK, Machac J, Krynyckyi BR: Reverse echelon node and a lymphatic ectasia in the same patient during 
breast lymphoscintigraphy: the importance of injection and imaging technique. $\mathrm{Br} J$ Radiol 2004, 77: 1053-1056.

11. Goyal A, Douglas-Jones AG, Newcombe RG, Mansel RE: Effect of lymphatic tumor burden on sentinel lymph node biopsy in breast cancer. Breast J 2005, I I: I88-194.

12. Burak WE Jr, Walker MJ, Yee LD, Kim JA, Saha S, Hinkle G, Olsen JO, Pozderac R, Farrar WB: Routine preoperative lymphoscintigraphy is not necessary prior to sentinel node biopsy for breast cancer. Am J Surg 1999, 177:445-449.

13. McMasters KM, Wong SL, Tuttle TM, Carlson DJ, Brown CM, Dirk Noyes R, Glaser RL, Vennekotter DJ, Turk PS, Tate PS, Sardi A, Edwards MJ: Preoperative lymphoscintigraphy for breast cancer does not improve the ability to identify axillary sentinel lymph nodes. Ann Surg 2000, 23 1:724-731.

14. Harlow SP: Is preoperative lymphoscintigraphy needed for sentinel node procedures in breast cancer? Annals of Surgical Oncology 2005, I 2:515-516.

15. Kim D, Kim S, Kim C, Machac J, Krynyckyi B: The effects of lymphoscintigraphy (LS) on morbidity reduction during sentinel lymph node biopsy (SLNB): A comparative study of the literature [abstract]. Oral presentation at the 4th Biennial International Sentinel Node Congress: Los Angeles 2004:P7. 3-6 December 2004

16. Kaleya RN, Heckman JT, Most M, Zager JS: Lymphatic mapping and sentinel node biopsy: a surgical perspective. Semin Nucl Med 2005, 35:129-134.

17. Mariani G, Erba P, Villa G, Gipponi M, Manca G, Boni G, Buffoni F, Castagnola F, Paganelli G, Strauss HW: Lymphoscintigraphic and intraoperative detection of the sentinel lymph node in breast cancer patients: the nuclear medicine perspective. J Surg Oncol 2004, 85: I I2-I 22.

18. Pelosi E, Bello M, Giors M, Ala A, Giani R, Bussone R, Bisi G: Sentinel lymph node detection in patients with early-stage breast cancer: comparison of periareolar and subdermal/peritumoral injection techniques. J Nucl Med 2004, 45:220-225.

19. Pelosi E, Ala A, Bello M, Douroukas A, Migliaretti G, Berardengo E, Varetto T, Bussone R, Bisi G: Impact of axillary nodal metastases on lymphatic mapping and sentinel lymph node identification rate in patients with early stage breast cancer. Eur J Nucl Med Mol Imaging 2005 in press. DOI: 10.1007/s00259-005-17979

20. Maza S, Thomas A, Winzer KJ, Huttner C, Blohmer JU, Hauschild M, Richter M, Krossin T, Geworski L, Zander A, Guski H, Munz DL: Subareolar injection of technetium-99 m nanocolloid yields reliable data on the axillary lymph node tumour status in breast cancer patients with previous manipulations on the primary tumour: a prospective study of 117 patients. Eur J Nucl Med Mol Imaging 2004, 3 I:67I-675.

21. Ellis RL, Seifert PJ, Neal CE, Pavolka KR, Mann JL, Malafa MP, Wichterman KA, Ross DS, Dunnington GL: Periareolar injection for localization of sentinel nodes in breast cancer patients. Breast 2004, 10:94-100.

22. Kim SH, Kim SC, Kim DW, Kim YJ, Youssef IM, Kim CK, Machac J, Krynyckyi BR: Can different arm and body positions help in detecting more sentinel lymph nodes (SN) during lymphoscintigraphy (LS) [abstract]? J Nucl Med 2005, 46(supplement 2):405P.

23. Kim SH, Kim SC, Kim DW, Machac J, Kim CK, Krynyckyi BR: The effect of different arm positions on sentinel node localization during lymphoscintigraphy [abstract]. J Nucl Med 2005, 46(supplement 2):405P.

24. Kim S, Youssef I, Kim CK, Machac J, Krynyckyi BR: Prominent lymphatic channels simulating sentinel nodes: The utility of standing and delayed views in delineating the true number and position of nodes and the implications for further morbidity reduction. Clin Nucl Med 2005 in press.

25. Pierini $A$, Dworkin $H J$ : Is the upright position more sensitive than the supine position in breast cancer sentinel node lymphoscintigraphy? Clin Nucl Med 200I, 26:823-825.

26. Krynyckyi BR, Kim CK, Shafir MK, Mosci K, Machac J: Breast cancer and its management, the utility and technique of lymphoscintigraphy. Nuclear Medicine Annual 2003:131-169.

27. Krynyckyi BR, Singh G, Colon D, Kim CK, Travis A, Kim SC, Machac J: Letter to the Editor. Eur J Surg Oncol 2005, 31:805-806.

28. Kim S, Krynyckyi BR, Fedorciw BJ, Kim CK: Extremely indirect dermal lymphatic channels: value of areolar-cutaneous junc- tion injection technique for breast lymphoscintigraphy. Curr Surg 2005, 62:335-337.
Publish with Bio Med Central and every scientist can read your work free of charge

"BioMed Central will be the most significant development for disseminating the results of biomedical research in our lifetime. "

Sir Paul Nurse, Cancer Research UK

Your research papers will be:

- available free of charge to the entire biomedical community

- peer reviewed and published immediately upon acceptance

- cited in PubMed and archived on PubMed Central

- yours - you keep the copyright 